RMC simulation of the experimental structure factor was successfully applied to generate a reliable 3-dimensional atomic configuration. Several partial atomic pair correlation functions, like the $\mathrm{g}_{\mathrm{SiO}}(\mathrm{r}), \mathrm{g}_{\mathrm{BO}}(\mathrm{r})$, $\mathrm{g}_{\mathrm{OO}}(\mathrm{r})$, $\mathrm{g}_{\mathrm{SiSi}}(\mathrm{r}), \mathrm{g}_{\mathrm{SiB}}(\mathrm{r}), \mathrm{g}_{\mathrm{NaO}}(\mathrm{r}), \mathrm{g}_{\mathrm{BaO}}(\mathrm{r}), \mathrm{g}_{\mathrm{ZrO}}(\mathrm{r})$ and most of the corresponding coordination number distributions has been revealed providing information on the short and intermediate range order.

The Si-O network proved to be highly stable consisting of slightly modified $\mathrm{SiO}_{4}$ units. The B-O surrounding proved to be more complex. We have found that two characteristic well resolved first neighbour B-O distances are present at $1.40 \AA$ and $1.60 \AA$. The latter agrees with the Si-O first neighbour distance, which is also at $1.60 \AA$. From the detailed analyses of the B-O and O-B coordination number distributions we have established that both 3- and 4-fold coordinated boron atoms (denoted as ${ }^{[3]} \mathrm{B}$ and ${ }^{[4]} \mathrm{B}$ ) are present.

We suppose that the boron atoms partly form a mixed continuous network with Si-O network, where several different mixed ${ }^{[4]} \mathrm{B}-\mathrm{O}-\mathrm{Si}$ and ${ }^{[3]} \mathrm{B}-\mathrm{O}-\mathrm{Si}$ linkages are present in agreement with the findings of NMR $[4,5]$ and Raman spectroscopy [6].

The work was supported by grants OTKA-42495, EC HPRI-RII3-CT-2003-505925, DE-AC52-06NA25396.

[1] Chun K.S., Kim S.S., Kang C.H., J. Nuclear Materials 2001, 298,150

[2] Fábián M., Sváb E., Mészáros Gy., Révay Zs., Proffen Th, Veress E., J. Non-Cryst. Solids 2007 , doi:10.1016/j.jnoncrysol.2007.02.030

[3] McGreevy R.L., Pusztai L., Molec. Simul. 1998, 1, 359.

[4] Roderick J.M., Holland D., Howes A.P., Scales C.R., J. NonCryst. Solids 2001, 293, 746.

[5] Du L.S., Stebbins J.F., J. Non-Cryst. Solids 2003, 315, 239.

[6] Okuno M., Zotov N., Schmücker M., Schneider H., J. NonCryst. Solids 2005, 351, 1032.

\section{MS23 04}

Magnetic phase transition of $\mathrm{FeS}$ at high pressures Shigeaki Ono $^{\mathrm{a}, \mathrm{b}}$, ${ }^{\mathrm{a}} I F R E E$, JAMSTEC, Japan. ${ }^{\mathrm{b}}$ Department of Earth Science, University College London, U.K.

E-mail: shigeaki.ono@ucl.ac.uk

Keywords: magnetic structural phase transition, iron sulfide, high-pressure research

According to the cosmochemical arguments and the seismological data, the Earth's core must contain some light elements. However, the nature of the light element is still uncertain, and the major proposed candidates have been $\mathrm{C}, \mathrm{Si}, \mathrm{O}, \mathrm{H}$, or $\mathrm{S}$. Therefore, it is important to understand the phase relationships of iron alloys at high pressures and high temperatures. In this study, we conducted high-pressure experiments and ab inito calculations to investigate the phase transitions and the physical properties of iron sulfide. In the case of highpressure experiments, the laser-heated diamond anvil cell combined with the synchrotron X-ray diffraction technique was used [1]. We also used the first-principle calculations to investigate the magnetic property of highpressure phase, which was discovered in the high-pressure experiments [2]. According to previous studies at ambient temperatures, FeS exhibits the following sequence of highpressure phase transitions: troilite (FeS-I), low-P MnP phase (FeS-II), monoclinic phase (FeS-III). In our highpressure experiments, we confirmed that the monoclinic phase was stable up to $40 \mathrm{GPa}$. Above $40 \mathrm{GPa}$, the sample was heated to $1000-2000 \mathrm{~K}$ to induce the phase transition. After heating, a new high-pressure phase (high-P MnP phase) was observed. This high-P MnP phase (FeS-VI) remained stable at pressures higher than $120 \mathrm{GPa}$. We found a significant discrepancy between low-P MnP and high-P MnP phases. The discontinuities for the unit cell volume and the cell parameters between two phases were observed. As the structure of low-P MnP phase is identical to that of high-P $\mathrm{MnP}$ phase, these discontinuities indicated that an unknown type of phase transition must occur. Next, we investigated the magnetic properties and the spin configurations of these phases using the ab inito calculations. Previous study [3] confirmed that the low-P $\mathrm{MnP}$ phase was antiferromagnetic state. The same results were confirmed in our calculations. We also calculated the non-magnetic state for the MnP structure. The calculated results showed that the non-magnetic $\mathrm{MnP}$ structure was more stable than anti-ferromagnetic $\mathrm{MnP}$ structure at high pressures. The volume and cell parameters of nonmagnetic $\mathrm{MnP}$ structure were in good agreement with those of high-P MnP phase observed in our experiments. Therefore, the magnetic transition of the $\mathrm{MnP}$ structure occurred at high pressures. The high-pressure stability limit of the high-P MnP phase was also investigated. We found that the phase transition from the high-P MnP phase to the CsCl-type phase occurs at about $300 \mathrm{GPa}$. Thus, the high-P MnP phase is stable at pressures corresponding to the lower mantle and the outer core. In contrast, the $\mathrm{CsCl}$ type phase is stable in the inner core. Our new findings can contribute to the understanding for the nature of the Earth's core.

[1] Ono S. et al., J. Appl. Phys., 2005, 97, 073523.

[2] Ono S., Kikegawa, T., Am. Mineral., 2006, 91, 1941.

[3] Martin, P. et al., Mineral. Mag., 2001, 65, 181.

\section{MS23 O5}

Sound velocities of $\mathrm{MgSiO}_{3}$ perovskite and postperovskite: A constraint on the D" discontinuity

Motohiko Murakami ${ }^{\text {a }}$ Institute for Study of the Earth's Interior, Okayama University, Yamada 827, Misasa, Tottori, 682-0193 Japan.

E-mail:mthk@misasa.okayama-u.ac.jp

Keywords: Brillouin scattering, elasticity, postperovskite, D“ discontinuity

Recent discovery of post-perovskite phase transition has important implications for interpretation of the D" layer at the base of Earth's mantle. Knowledge of the pressure dependence of acoustic wave velocities of post- perovskite phase provides essential and direct constraints for the seismic wave velocity profile at the $\mathrm{D}$ " region. In this study, we report the aggregate shear wave velocities in $\mathrm{MgSiO}_{3}$ post-perovskite phase by Brillouin spectroscopy in a diamond anvil cell (DAC) up to $173 \mathrm{GPa}$, in combination with infrared laser annealing of the samples. High-pressure Brillouin scattering measurements of sound velocities were carried out at room temperature in a symmetric diamond anvil cell with a 60-degree angular aperture. An argon-ion laser at a wavelength of $514.5 \mathrm{~nm}$ and $25-150 \mathrm{~mW}$ of power was used as a probe beam. The incident laser was focused to a beam size of $\sim 30 \mu \mathrm{m}$ in diameter on the sample. The scattered light was analyzed by a six-pass tandem Fabry-Perot interferometer. All measurements were performed in a platelet scattering geometry. Polycrystalline samples were synthesized in situ 
in a $\mathrm{DAC}$ from an $\mathrm{MgSiO}_{3}$ gel starting material by heating with a carbon dioxide laser. A pre-pressed plate of $\mathrm{MgSiO}_{3}$ gel was loaded into a $\sim 60 \mu \mathrm{m}$ hole drilled in a rhenium gasket, sandwiched between plates of $\mathrm{NaCl}$, and Pt fragments were also loaded as a pressure standard. Angle-dispersive $\mathrm{x}$-ray diffraction measurements were conducted at BL10XU of SPring- 8 for precise pressure determination and phase identification under extreme high pressure condition in the DAC. The new results, together with our recent sound velocity data for $\mathrm{MgSiO}_{3}$ perovskite provide tight constraints on the seismic behavior at the base of the mantle. Based on our new results, we will discuss on the $\mathrm{D}^{\prime \prime}$ seismic discontinuity. 